\title{
Hybrid Solar and Wind Power Generation in Saudi Arabia
}

\author{
Omar S. Alzaid ${ }^{1}$, Basharat Salim², Jamal Orfi ${ }^{2,3}$, Salah Khan ${ }^{1,3} \&$ Hassan Alshehri ${ }^{2}$ \\ ${ }^{1}$ Sustainable Energy Technologies (SET) Center, King Saud University, Riyadh, Saudi Arabia \\ ${ }^{2}$ Mechanical Engineering Department, King Saud University, Riyadh, Saudi Arabia \\ ${ }^{3}$ KA.CARE Energy Research and Innovation Center at Riyadh, Saudi Arabia \\ Correspondence: Omar Alzaid, Sustainable Energy Technologies (SET) Center, King Saud University, Riyadh, \\ Saudi Arabia. Tel: 966-592-999-323. E-mail: 438105468@student.ksu.edu.sa, os.alzaid@ gmail.com
}

Received: November 9, 2020

Accepted: Novembr 29, $2020 \quad$ Online Published: November 30, 2020

doi:10.5539/eer.v10n2p25

URL: https://doi.org/10.5539/eer.v10n2p25

\begin{abstract}
Solar and wind energy systems are attractive hybrid renewable energy systems suitable for various applications and most commonly for power generation. Compared to standalone wind and solar devices, hybrid systems have several advantages, including requiring lesser or no storage devices, being more reliable, damping the daily and seasonal variations and ensuring constant energy flows. This work aims to conduct a feasibility study and a performance analysis of a hybrid wind and solar photovoltaic (PV) power system in selected regions in the Kingdom of Saudi Arabia (KSA). A detailed review on the potential of PV, wind energy and hybrid energy systems in KSA, to reason out the potential areas of study, has identified two sites to be selected to carry out the investigation. A small size power system driven by solar and wind energy has been modeled and simulated for a year period in the selected locations. Various configuration schemes of integrated solar and wind with storage devices for such a small capacity system have been proposed and their respective performances have been evaluated. Techno-economic aspects have been included. The simulation results indicated that the developed model shows a promising future of implementing the renewable energy system in the eastern and southern regions of the Kingdom.
\end{abstract}

Keywords: renewable energy, solar, wind, Hybrid, power generation, small scale

\section{Introduction}

The increasing demands of energy to meet human requirements through traditional energy production have led to an increase in carbon foot-print, global warming and earth temperature. This led to search for more environmentally friendly renewable energy sources such as solar and wind energy. Saudi Arabia has high solar radiation at all locations with annual average wind speeds in most locations between $6.0 \mathrm{~m} / \mathrm{s}$ and $8.0 \mathrm{~m} / \mathrm{s}$. Several studies, (Allhibi, Chowdhury, Zaid, Loganathan, \& Alam, 2019; Zella et al., 2015; Tlili, 2015; Md. Mahbub, Rehman, Meyer, \& Al-Hadhrami, 2011; Al Sharafi, 2011) have shown that the Kingdom has a high potential to produce energy through solar PV and wind. Moreover, there are many remote areas which cannot be feasibly connected to the main electric grid. This requirement of energy at these places can be met through the use of hybrid solar PV and wind energy with or without a storage system. Earth receives $174 \mathrm{PW}$ of solar radiation coming from the sun (Martin \& Goswami, 2005). The quantity of solar radiation is affected by the geographical location, the season, the time of day and the climate conditions (Breza, 2013). 30\% of solar radiation is reflected back and $70 \%$ is absorbed by the earth's atmosphere and surface (water and land) (Mills, 2004). The diffuse radiation is the solar radiation scattered by clouds, dust, ground, or other matter (Dzimano, 2008). Solar power can either be converted to electricity by using the PV effect (Kalogirou, 2009) or can be converted into thermal energy through solar thermal effects. Wind is present everywhere and is the result of deferential temperature and pressure on Earth. It is affected by the terrain and topography of a place. The conversion of wind energy into electrical or mechanical power requires wind converters called wind turbines. For electrical power generation from wind energy, horizontal axis wind turbines (HAWT) are used, whereas for mechanical power generation, vertical axis wind turbines (VAWT) are used. Since sunlight is available only during daytime and wind is intermittently available, a hybrid combination of the two assisted with a storage system would provide continuous and uninterrupted power supply at remote areas. Many studies (Zella et al., 2015; Manwell, McGowan, \& Rogers, 2009; Almasoud, \& Gandayh, 2015; Sahin, Rehman, \& Al-Sulaiman, 2017; Alqahtani, 
2016) have been carried out in the Kingdom, by considering geographical "position on the Earth" and meteorological "weather forecasting" locations, economics of solar energy and load forecasting. These studies indicate the existence of many locations in the Kingdom where solar energy conversion can be carried out easily through the use of PV systems. The annual average daily global horizontal irradiance was found to be in the range between $5700 \mathrm{Wh} / \mathrm{m}^{2}$ to $6700 \mathrm{Wh} / \mathrm{m}^{2}$. Ahmet and Suleiman (2017) have developed Angstrom models to estimate the global solar radiation as a function of sunshine duration while taking into consideration the effect of temperature on PV efficiency during the calculation of the PV power output. Almarshoud (2016) simulated the solar data using RETScreen by utilizing yield factor, capacity factor and performance ratio as indicators to determine the performance characteristics of PV systems. Garni and Awasthi (2017) developed an approach based on a geographical information system and Analytic Hierarchy Process to find the most suitable site for solar PV utilization in Saudi Arabia. They found that the generated power potential could reach 8,330,807 GWh per year. Garni and Awasthi (2017) discussed the method for site selection for PV utilization using the geographical information system and multi criteria decision making techniques with taking into concsideration the economic and technical factors and power maximization.

Wind energy is one of the most promising clean, natural, and plentiful renewable source of energy in the world. The wind energy system is cost-effective with availability through day and night, and is environment friendly. It can provide electrical power for rural and off-grid areas and replace traditional power generation systems such as diesel generators. Many studies (Rehman \& Ahmad, 2004; Rehman, 2005; Rehman \& Sahin, 2014; Eltamaly, 2013; Shahid, Al-Hadhrami, \& Rahman, 2013) have been conducted in Saudi Arabia for wind energy utilization. Most of the studies focused on site selection and wind data analysis of the sites. They also recommended the type of wind turbines that could be used at these locations. Rahman and Sahin (2014) have compared the cost of pumping water from a $50 \mathrm{~m}$ head for different sites using HOMER. As expected the cost was less where wind speed was more. Eltamaly (2013) presented a specific procedure to choose an accurate location out of many others for a wind turbine while taking into consideration the minimum price of generated wind energy. Shahid et al. (2013) have conducted a feasibility study to develop a $75 \mathrm{MW}$ wind power plant with long term analysis of wind speed data in coastal areas of Saudi Arabia. The simulated wind power plant was composed of $600 \mathrm{~kW}$ wind turbines of different combinations with 50-meter hub height. HOMER was used to develop the techno-economic assessment. Mujahid et al. (2018) simulated a grid-connected feasibility study of a $100 \mathrm{MW}$ wind farm at five different locations within Saudi Arabia by carrying out a simulation using RETScreen. They calculated payback periods of the models. A higher capacity factor and a lower payback period were found for locations with higher wind speed. Esmail et al. (2013) have conducted a simulation study of hybrid solar and wind power system for powering a desalination system with a constant desalination load demand using HOMER and MATLAB. By Using the Loss of power supply method for configuration of the hybrid system, the results show that for the option of $12 \mathrm{~h} /$ day, the optimum system of 1-kW consisting of 2 wind turbines, $40 \mathrm{PV}$ modules and 6 batteries with a minimum cost of energy of $0.624 \$ / \mathrm{kWh}$, while for the $24 \mathrm{~h} /$ day option, the optimum system consists of 6 wind turbines, 66 PV modules and 16 batteries with a minimum cost of energy of 0.672 $\$ / \mathrm{kWh}$. Naif et al. (2009) studied the wind characteristics in the Qassim region of Saudi Arabia. The data were collected from December 5, 1995 to October 24, 1998. The analysis shows that the annual mean wind power densities were 55,73 , and $87 \mathrm{~W} / \mathrm{m}^{2}$ at 20,30 and $40 \mathrm{~m}$, respectively, and the annual net energies were estimated as $6554.7,7634.8$, and $8563.5 \mathrm{MWh}$ with a plant capacity factor of $27.2 \%, 31.7 \%$, and $35.5 \%$ corresponding to hub heights of $60,80,100 \mathrm{~m}$, respectively. The calculation showed that the wind turbine with a cut-in speed of $3.5 \mathrm{~m} / \mathrm{s}$ can produce energy $68 \%$ of the time at a hub height of $60 \mathrm{~m}$, and $73 \%$ of the time at a hub height of 100 $\mathrm{m}$. Al-Ghussain et al. (2018) conducted a techno-economical study on a hybrid PV wind energy system to reduce the electrical bill of a cement plant in Al-Tafilah, Jordan, where the wind speed is about $2.94 \mathrm{~m} / \mathrm{s}$. They proposed a hybrid system of $23.75 \mathrm{MW}$ from PV, 26 MW from wind with 16.8 MWh lithium-ion batteries as a storage system. The results showed that for a payback period of 3.44 years, the net present value of the hybrid and batteries systems is $\$ 206.63 \mathrm{M}$ and the cement factory electricity bill would be reduced annually by $\$ 21.58 \mathrm{M}$. Also, the emissions of $\mathrm{CO} 2$ would be reduced by 71,373 tons. Samrat et al. (2015) presented a modeling and simulation study using MATLAB/Simulink under different load and weather conditions for electrification of an island in Malaysia. His study included a standalone system consisting of a battery storage system and a hybrid solar PV and wind energy power supply system. He found that solar-only or wind-only systems cannot work alone and proposed that the hybrid system can operate under various load and weather conditions. Lee-Jones (2016) conducted a financial feasibility study of a small-scale hybrid wind and PV system providing electricity $(31 \mathrm{~kW})$ to meet the demand for small residential applications using RETScreen. Four designs have been proposed and evaluated for the hybrid systems with $15.2 \mathrm{~kW}$ from wind and $21.5 \mathrm{~kW}$ from PV. Bhattacharjee and Acharya (2015) studied the performance of a hybrid PV and wind system, located in the state 
of Tripura in India. This area has low wind typography. This study presented a model for small-scale applications and developed a techno-economic analysis for hybrid a PV-wind system for an educational building. They developed an optimization model using HOMER. The study results show that the power is generated principally by solar PV all year round. However, a significant amount of power can come from the wind system in the middle of the year. Also, at this time the power production of the solar PV was less. Bekele and Tadesse (2012) made a feasibility study for a small-scale hybrid PV and wind energy system in Ethiopia. The study was conducted through HOMER and GIS software and the data were obtained from governmental and national sources. The load profile was built to fill the basic needs of the community which was calculated to be $1424 \mathrm{~kW}$. Different system configurations have been obtained. The results show that the wind and solar resources together with a diesel generator and battery system as a backup could be used for better reliability of rural electrification. Benghanem (2011) studied the optimum angle for solar panel or collector and pointed out that the yearly average optimum tilt angle is equal to the latitude of the studied site. Elhadidy (2007) conducted and examined the potential of using hybrid wind and diesel system on Dharan, Saudi Arabia. The results indicaded that using a set of $150 \mathrm{~kW}$ will increase by $48 \%$ more energy than the $600 \mathrm{~kW}$ wind turbines for supling an annual demand load of $3512 \mathrm{MWh}$. It can be observed from above literature that: higher global solar radiation was found in the summer compared to the winter and maximum power is available at lower temperatures. Also, higher wind speed values were in the summer and the lower ones in the winter. Furthermore, small capacity size of wind turbines tends to produce more energy than higher capacity ones. Moreove, the use of hybrid system such as a solar PV and wind system should be cost-effective and technically feasible. As well, the solar PV and wind hybrid system can provide power with minimum or no storage and can continuously supply power. This study focuses on finding suitable hybrid options for two locations in the Kingdom which have different solar and wind conditions. The detailed analysis is presented first for Sharourah which is located deep in the largest desert region of the Arabian Peninsula where many villages and areas are without continuous power supply, and second for Hafar Al-Batin which is located in the Eastern Region of Saudi Arabia. The required load of the hybrid solar/wind system for this study has been set to $5 \mathrm{~kW} / \mathrm{h}$.

\section{Modeling}

\subsection{Solar and Wind Power Estimation}

The following is a presentation of the applied methodology in this research describing the workflows, mathematical models and simulation sequences of the developed solar and wind hybrid system. A mathematical model was developed for each part of the system, then all the parts were combined together for continuous power supply. The mathematical model for the PV system consists of two main steps. The first step was an analysis of the sun angles to find the best tilt angle for high solar radiation striking the PV modules. This analysis was based on the solar data from the recognized governmental sector. The second step was the development of the main equation for the solar PV system. Developing the wind turbine mathematical model first required matching the manufacture's specifications of the wind turbine with wind data provided by the recognized governmental sector. Second, an analysis of wind data was conducted to estimate the wind potential in the selected location. Following that, the mathematical model for the battery storage along with inverter was developed. All the system parts were then combined together and a mathematical model of the hybrid system reliability was developed to check if the system continuously produce or loss the required power sypply at any time. Moroever, an assessment of the system sizing including the total numbers of PV panels, wind turbines, batteries and inverter were carried out. Finally, an economical model was conducted. Figure 1 shows the schematic of the hybrid system arrangement.

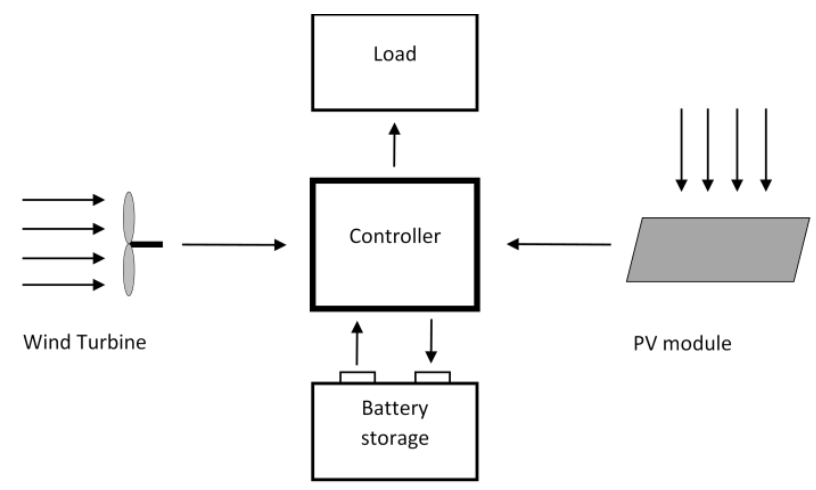

Figure 1. Schematic diagram of proposed hybrid system 
From Figure 1, when the sun stricks into the PV array and also the wind blows toward the wind turbine, the produced power is being controlled by the controller. The latter is managing the supply of required load and at the same time charging and discharging the battery. Kalogirou (2009) and, Manwell, McGowan, and Rogers (2009) have been used for the mathematical models for the power estimation of solar energy and wind energy whereas the cost estimation of different configurations was carried out as per methods given in (Diaf, Diaf, D., Belhamel, Haddadi, \& Louche, 2007; Yang, Shen, \& Liao, 2003).

The power output of the PV array $\mathrm{P}_{\mathrm{i}}(\mathrm{W})$, can be calculated from,

$$
P_{i}=A_{c} G_{T, i} \eta_{m p} \eta_{e}
$$

Where $\left(P_{i}\right)$ is the out power from a single PV panel $(W),\left(A_{c}\right)$ is the array area $\left(\mathrm{m}^{2}\right),\left(G_{T, i}\right)$ is the incident solar radiation on the array $\left(\mathrm{W} / \mathrm{m}^{2}\right),\left(\eta_{\mathrm{mp}}\right)$ is the maximum power point efficiency of the array $(\%)$, and $\left(\eta_{\mathrm{e}}\right)$ is the efficiency of any power-conditioning equipment $(\%)$. The mechanical power developed by a wind turbine, $\mathrm{P}_{\mathrm{m}}$ (W), can be expressed as,

$$
P_{m}=\frac{1}{2} \rho A_{t} C_{p} \times V_{w}^{3}=\frac{1}{2} \rho A_{t} C_{p} \times\left(\frac{\omega_{m} R}{\lambda}\right)^{3}
$$

Where $(\rho)$ is the air density $\left(\mathrm{kg} / \mathrm{m}^{3}\right),\left(\mathrm{A}_{\mathrm{t}}\right)$ is the rotor swept area $\left(\mathrm{m}^{2}\right),\left(\mathrm{C}_{\mathrm{p}}\right)$ is the power coefficient, $\left(\mathrm{V}_{\mathrm{w}}\right)$ is the wind speed $(\mathrm{m} / \mathrm{s}),\left(\omega_{\mathrm{m}}\right)$ is the angular rotor speed $(1 / \mathrm{rad}),(\mathrm{R})$ is the rotor radius $(\mathrm{m})$,

$(\lambda)$ is the tip speed ratio. Where the tip speed ratio $\lambda$ is given by

$$
\lambda=\frac{\omega_{m} R}{V_{w}}
$$

The required capacity of the battery can be calculated by:

$$
C_{B}=\frac{h * P_{L}}{\eta_{\text {Batt }} * \eta_{\text {wiring }} * \eta_{\text {inv }} * D O D}
$$

Where $(\mathrm{h})$ is the number of hours, $\left(P_{L}\right)$ is the load demand $(\mathrm{W}),\left(\eta_{\text {Batt }}\right)$ is the efficiency of the battery, $\left(\eta_{\text {wiring }}\right)$ is the loss by the electrical wiring, $\left(\eta_{i n v}\right)$ is the loss by the invertor/charger/controller. DOD refers to the maximum depth of discharge, generally between $30 \%$ and $50 \%$.

The batteries have two processes: charging and discharging. During the charging process, the load demand is satisfied by the hybrid system and the system has extra power output, which is stored in the batteries. At hour, $t$, the available battery storage capacity, $\mathrm{C}_{\mathrm{B}}(\mathrm{t})$, can be described by,

$$
\begin{gathered}
C_{B}(t)=C_{B}(t-1) *(1-\sigma)+\left(P_{T}(t)-\frac{P_{L}(t)}{\eta_{\text {inv }}}\right) \eta_{B a t t} \\
\mathrm{P}_{T}(\mathrm{t})=n_{P V} \mathrm{P}_{P V}+n_{W} \mathrm{P}_{W}
\end{gathered}
$$

where $\mathrm{P}_{\mathrm{T}}(\mathrm{t})$ is the total output power generated by the hybrid system at hour, $\mathrm{t}$, and $\sigma$ is the self-discharge rate of the batteries, $n_{p v}$ and $n_{w}$ are the number of PV panels and wind turbines respectively. When the load demand is not satisfied by the hybrid system, the batteries go through the discharging process. This process at time, $t$, can be described by,

$$
C_{B}(t)=C_{B}(t-1) *(1-\sigma)-\left(\frac{P_{L}(t)}{\eta_{i n v}}-P_{T}(t)\right)
$$

Moroever, $\eta_{B a t t}$, during the discharging process is set to one, while during the charging process, it is set to a value between 0.65 and 0.85 , depending on the charging current. As per the manufacturer, the self-discharge is equal to $0.1 \%$ per day. Finally, the battery charging capacity at any time is limited by the following constraint: $C_{B \min } \leq C_{B}(t) \leq C_{B \max }$, where $C_{B \max }$ is the maximum allowable storage capacity and $C_{B} \min$ is the minimum allowable storage capacity. $C_{B \text { max }}$ is equal to the nominal capacity value $\left(C_{B \text { max }}=C_{B a t t}\right)$ and the minimum storage capacity value $\left(C_{B} \min \right)$ is calculated from the maximum depth of discharge, DOD, its within the range from $30 \%$ to $50 \%$, depending on the manufacturer recommendation.

$$
C_{B \min }=(1-D O D) * C_{B a t t}
$$




\subsection{Loss of Power Supply Probability (LPSP)}

The dependability and reliability of the configuration of stand-alone system is considered as the most important design aspect; Therefore, the system shall supply the demand power continuously without any failure, The loss of power supply probability can give the optimum configuration of the proposed system, LPSP, is defined as the ratio of the loss of power supply, LPS, to the power required by the load during a defined time period. (Mokheimer, Sahin, Al-Sharafi, \& Ali, 2013; Diaf, Diaf, D., Belhamel, Haddadi, \& Louche, 2007; Yang, Shen, \& Liao, 2003).

$$
\begin{gathered}
L P S P=\frac{\sum_{t_{0}}^{t_{\max } L P S}}{\sum_{t_{0}}^{t_{\max } L O A D}} \\
L S P(t)=P_{\text {total }}(t) * \Delta t-\left(\left(P_{P V}(t)+P_{W T}(t)\right) \Delta t+C_{B a t}(t-1)-C_{B a t . m i n}\right) * \eta_{\text {inv }}
\end{gathered}
$$

Where $\left(\mathrm{P}_{\text {total }}\right)$ is the load demand, $(\Delta t)$ is the time step (one hour) and $\mathrm{C}_{\text {batt }}(\mathrm{t}-1)$ is status of the battery at the last hour.

\subsection{Wasted Energy and Excess Energy}

The wasted energy, WE (W), is the energy which is being produced by the system and exceeds the demand load and is not being used. It is described by Diaf et al. (2007); Yang, Shen, and Liao (2003).

$$
W E(t)=P_{\text {load }}(t) * \Delta t-\left(\frac{P_{\text {load }}(t)}{\eta_{\text {inv }}} \Delta t+\left(\frac{C_{\text {Bat.max }}-C_{\text {Bat }}(t-1)}{\eta_{\text {char }}}\right)\right)
$$

The excess energy, EXEN (W), is defined as the wasted energy divided by the total energy produced by the hybrid system during the considered period. It is described by,

$$
\operatorname{EXEN}(t)=\frac{W E(t)}{E_{\text {total }}}
$$

\subsection{Economic Model and Cost Estimation}

In power generation systems, the most leading economic method for analyzing the benchmark cost is to subject it to the levelized cost of energy (LCOE) method. In this study, the LCOE method is used as the economic sizing model for choosing the lowest cost of energy (Esmail, Abdullah, Habib, \& Iyad, 2015). LCOE is described by (Mokheimer, Sahin, Al-Sharafi, \& Ali, 2013; Diaf et al., 2007; Fingersh, Hand, \& Laxson, 2006),

$$
\begin{gathered}
L C O E=\frac{C R F * I C C}{A P D_{\text {net }}}+A O E \\
\mathrm{AOE}=\frac{\mathrm{O} \& \mathrm{M}+\mathrm{LRC}}{A P D_{\text {net }}}
\end{gathered}
$$

Where the (LCOE) is the levelized cost of energy $(\$ / \mathrm{kWh}$ ) (constant $\$$ ), $(\mathrm{CRF})$ is the capital recovery factor $(\$),(I C C)$ is the initial capital cost (\$),(APDnet) is the net annual power demand (kWh/yr),(AOE) is the annual operating expenses $(\$),($ LCC) is the land lease cost $(\$),(\mathrm{O} \& M)$ is the operation and maintenance cost $(\$)$ and (LRC) is the replacement cost (\$).

CRF is calculated by,

$$
C R F=\frac{i *(1+i)^{n}}{(1+i)^{n}-1}
$$

Where (i) is annual discount rate and (n) is the system life in years.

\section{Results and Discussion}

The arrangement of the hybrid system depends on the storage capacity of the batteries, the hub height of the wind turbine and PV array area. The values used for the mathematical models of the hybrid system are,

(1) Battery storage capacities used are 0, 6, 12 and 24-hour storage with a life of 4 years,

(2) Wind turbines used have hub heights of $40 \mathrm{~m}, 60 \mathrm{~m}, 80 \mathrm{~m}$ and $100 \mathrm{~m}$ above ground with cut-in speeds of 3 $\mathrm{m} / \mathrm{s}$ or less.

(3) PV panels used are small and economical with a power rating of $300 \mathrm{~W}$ and an efficiency of $18 \%$ as per the 
NREL report (Fu, Remo, \& Margolis, 2018).

(4) Solar panels are to be fixed horizontally with a tilt angle equal to the latitude (Benghanem, 2011).

(5) System life is 20 years.

The operation, maintenance and replacement costs of all components are listed Table 1.

Table 1. Cost estimation of the wind and solar systems

\begin{tabular}{ccc}
\hline Description & Cost & Notes \\
\hline O\&M, wind turbine & $2.50 \%$ & of the total cost \\
LRC, wind turbine & $1 \%$ & of the total cost \\
O\&M, PV & $1 \%$ & of the total cost \\
of the total cost & years \\
LRC, PV & $1 \%$ & of the turbine \& tower cost \\
Life & 20 & of the turbine \& tower cost \\
Installation & $5 \%$ & Cost (\$) / power $(1 \mathrm{~kW})$ \\
Foundation & $5 \%$ & \\
Inverter, controller, charger & 500 & years \\
Interest rate & $2 \%$ & of the turbine \& tower cost(including controller and charger) \\
Battery replacement & 4 & of the turbine \& tower cost (including controller andcharger) \\
O\&M, inverter & $1 \%$ & Cost $\$$ ) / power $(1 \mathrm{~W})$ \\
LRC, inverter & $5 \%$ & Cost $(\$) /$ power $(1 \mathrm{~kW})$ \\
PV panels & 2.49 & of the total cost "turbine,tower and other related components" \\
Wind turbine & 2967 &
\end{tabular}

From Table 1, the cost of wind trurbine is taken as $2967 \$$ forevery $1 \mathrm{~kW}$ or $25 \%$ of the total cost of wind turbine "turbine, tower and other related components".

\subsection{Wind and Solar Analysis Observation}

The selected locations are Sharourah and Hafar Al-Batin cities, which lie in south and east of Saudi Arabia, respectively. The weather conditions were obtained from King Abdullah City for Atomic and Renewable Energy (KACARE). The wind data are for 2015-16 whereas the solar data are for 2014 -2016.

In Sharourah, the wind analysis of the 2015 data shows a minimum and maximum wind speed of $5 \mathrm{~m} / \mathrm{s}$ in January and $6.8 \mathrm{~m} / \mathrm{s}$ in April. The corresponding values for 2016 were $4.9 \mathrm{~m} / \mathrm{s}$ in October and $6.7 \mathrm{~m} / \mathrm{s}$ in March. The diurnal wind speeds for 2015 and 2016 show that $86 \%$ of wind speeds were found to be above $4 \mathrm{~m} / \mathrm{s}$ at a height of 40 meter above ground level. While for the other heights, the percentages were $88 \%, 90 \%, 91 \%$ and $92 \%$ at heights of 60, 80, 98 and 100 meters, respectively. The average wind speeds in Hafar Al-Batin were equal to or above $5 \mathrm{~m} / \mathrm{s}$ for all heights from the ground. The diurnal wind speeds for 2015 and 2016 show $88 \%$ of wind speeds were above $4 \mathrm{~m} / \mathrm{s}$ and they increased with height. Figures 2 and 3 show the diurnal wind speeds for 2015 and 2016 at Sharourah and Hafar Al-Batin. The maximum and minimum values of global solar irradiance in Sharourah were $7.8 \mathrm{~kW} / \mathrm{m}^{2} /$ day and $5 \mathrm{~kW} / \mathrm{m}^{2} /$ day, whereas for Hafar Al-Batin, the maximum and minimum values were $8.28 \mathrm{~kW} / \mathrm{m}^{2} /$ day and $3.24 \mathrm{~kW} / \mathrm{m}^{2} /$ day. It is observed that the solar irradiance for a PV panel with a tilted angle "equals to the location latitude angle" collect more solar radiation than for a horizontal surface (10). Figures 4 and 5 show the difference between the tiltet panel and horizontal panel in terms of solar irradiance.

The required load for this study has been set to $5 \mathrm{~kW} / \mathrm{h}$. The LPSP method was used in the design and configuration of the hybrid wind and solar power generation system with battery storage. Morover, the best economic system was chosen by using the lowest LOCE. A diesel generator (DG) was used to compare the payback time of the hybrid system since it is the available power production system at the two locations. Table 2 shows the economics for the DG. 
Table 2. Diesel generator economics

\begin{tabular}{|c|c|c|}
\hline Description & Cost & Unit \\
\hline Diesel Generator (DG) cost & 3219 & $\$$ \\
\hline DG cost - standby & 3219 & $\$$ \\
\hline Fuel cost & 0.1253 & $\$ / L$ \\
\hline Maintenance & 100 & Hours \\
\hline Maintenance cost & 100 & $\$$ \\
\hline DG fuel consumption & 4.08 & $\mathrm{~L} / \mathrm{h}$ \\
\hline DG life span & 15000 & Hours \\
\hline Project life & 20 & years \\
\hline DG units per project life & 12 & unit \\
\hline Diesel tank (150 gallon) & 1000 & $\$$ \\
\hline Maintenance (diesel tank) & 150 & \$/year \\
\hline Installation, foundation cost & $25 \%$ & $\mathrm{DG}+\operatorname{tank}$ \\
\hline Electrical, wiring, control & $30 \%$ & DG \\
\hline Tubes, feed pumps & $30 \%$ & $\mathrm{DG}+\operatorname{tank}$ \\
\hline Interest rate & $2 \%$ & \\
\hline DG standby fuel cost & $15 \%$ & DG cost \$/year \\
\hline DG standby (maintenance ) & $15 \%$ & DG cost \$/year \\
\hline
\end{tabular}
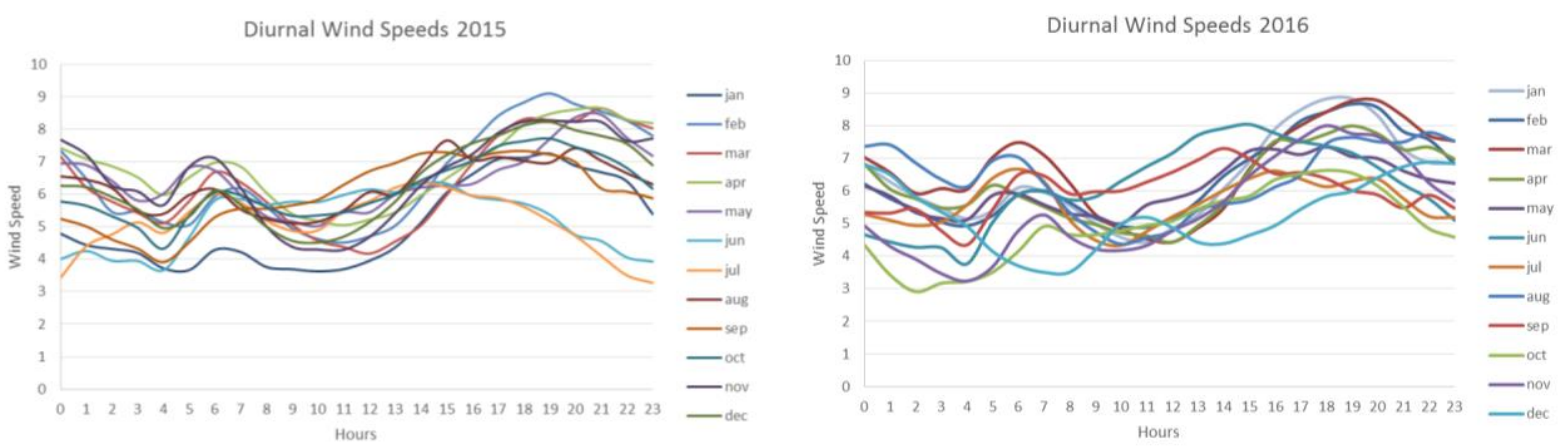

Figure 1. A-Diurnal wind speeds for 2015, B- Diurnal wind speeds for 2016, both at Sharourah
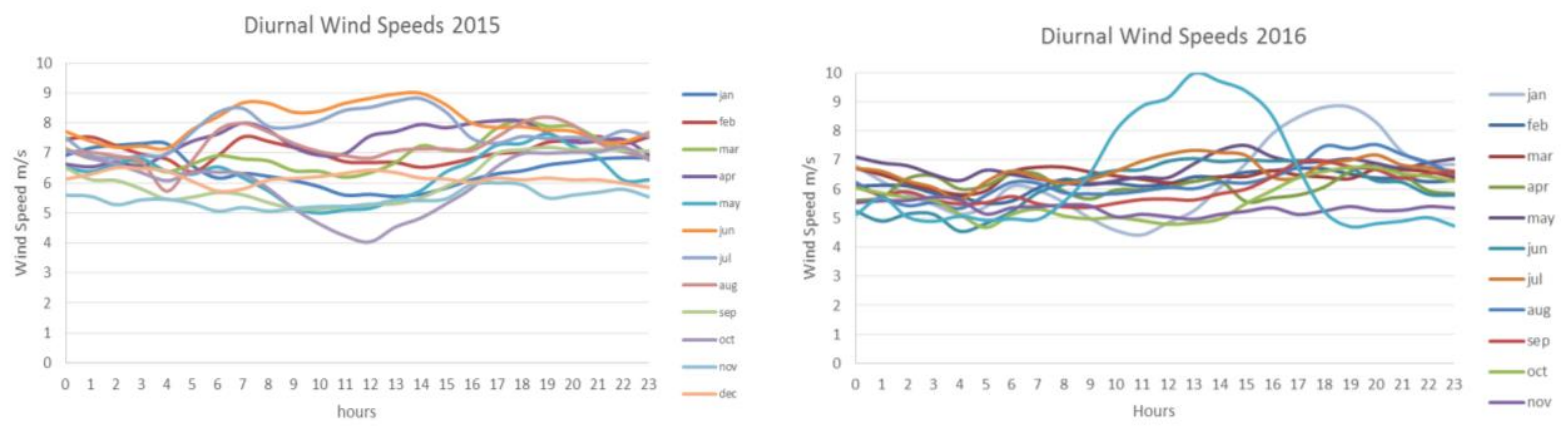

Figure 2. A-Diurnal wind speeds for 2015, B- Diurnal wind speeds for 2016, both at Hafar Al-Batin

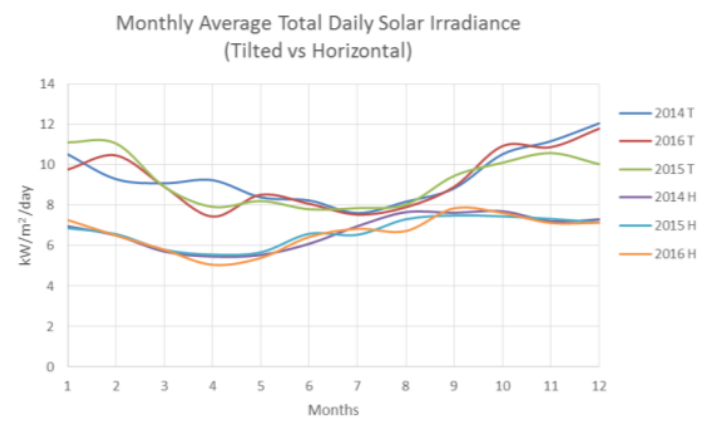

Figure 4. Solar irradiance at Sharourah, tilted vs. horizontal angle 


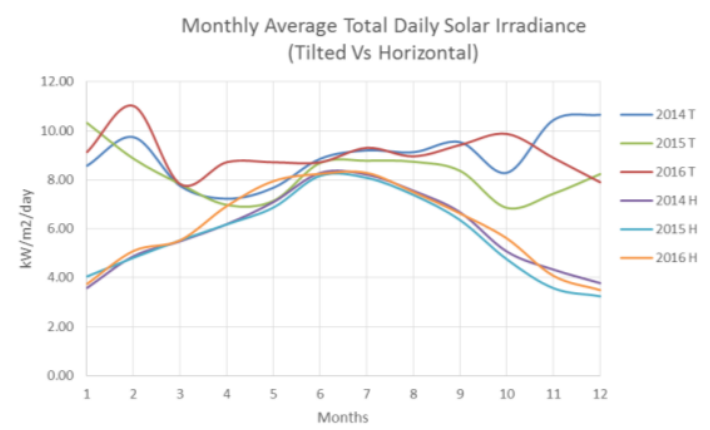

Figure 5. Solar irradiance at hafar albatin, tilted vs. horizontal angle

Various batteries were chosen from Diaf et al. (2007) and presented in Table 3.

Table 1. Battery types

\begin{tabular}{cccc}
\hline & Selected Batery & Nominal Selected capacity & \multirow{2}{*}{ Price $(\$)$} \\
\hline Manufacturer & Model & (Ah) & 465 \\
Concord & PVX-2120L & 253 & 208 \\
Concord & PVX-890 T & 102 & \\
\hline
\end{tabular}

Since the design of the system is fixed at 4 different capacity storage categories; it has been found that the battery will have a fixed price at each of the categories as per Table 4 .

Table 2. Battery comparison

\begin{tabular}{cccccc}
\hline \multicolumn{2}{c}{ Capacity Types } & \multicolumn{2}{c}{ PVX-2120L } & \multicolumn{2}{c}{ PVX-890T } \\
Hours & $\mathrm{kWh}$ & Quantity & Cost $(\$)$ & Quantity & Cost (\$) \\
\hline 24 & 350 & 116 & 53940 & 245 & 50960 \\
12 & 175 & 58 & 26970 & 143 & 29744 \\
6 & 87.5 & 29 & 13485 & 72 & 14976 \\
0 & 0 & 0 & 0 & 0 & 0 \\
\hline
\end{tabular}

The wind turbines were chosen based on the above constraints and a list of the chosen wind turbines is presented in Table 5.

Table 3. List of Wind Turbines

\begin{tabular}{ccccc}
\hline \multirow{2}{*}{ Turbine Model } & Rated Power $(\mathrm{kW})$ & & Speed $(\mathrm{m} / \mathrm{s})$ & Cut.out \\
\cline { 3 - 5 } & 5 & Cut.in & 12 & 18 \\
Redriven & 5.5 & 2 & 11 & 21 \\
ENAIR 70PRO & 3 & 2 & 12 & 15 \\
ENAIR E30 & 6.5 & 2 & 6 & 14 \\
Aventa av7 & 15 & 2 & 8.5 & 25 \\
KVA WIND 10-15 & 9.9 & 2.5 & 6.8 & 16 \\
TN535 & 3 & 2.5 & 12 & 25 \\
Aeolos h 3kW & 5 & 3 & 10 & 25 \\
Aeolos h 5kW & 5.5 & 3 & 12 & 60 \\
Britwind R9000 & 2 & 3 & 11 & 25 \\
Tuge 2 & 10 & 3 & 11 & 25 \\
Tuge 10 & 3.5 & 3 & 11 & 13 \\
Antaris 3.5 & 5.5 & 2.8 & 11 & 13 \\
Antaris 5.5 & 5 & 2.8 & 12 & 25 \\
H6.4-5KW Hummer & 10 & 3 & 11 & 25 \\
H10-8KW Hummer & & 3 & & \\
\hline
\end{tabular}


As depicted by Tables 3 and 4 that to cover the load demand $(5 \mathrm{~kW} / \mathrm{h})$, more batteries of model PVX-890T are needed compared to PVX-2120L, which means that more PVX-890T units are needed for the same load demand and therefore they require more space. Further, PVX-2120L has a lower cost for the 6 and 12-hour storage options, compared to the PVX-890T. Therefore, the PVX-2120L battery is chosen in this study in all the evaluated configurations. The battery capacity of each category has been calculated with taking into consideration the losses from the wiring, inverter, charger, controller, depth of discharge and the battery efficiency (shown in Table 6).

Table 4. Battery losses and efficiency

\begin{tabular}{cccc}
\hline Losses & \% & Losses & \% \\
\hline Battery eff & $80 \%$ & Inverter, controller, charger & $92 \%$ \\
DOD & $50 \%$ & Wiring & $95 \%$ \\
\hline
\end{tabular}

The PV modules were chosen based on the above constraints and a list of the chosen PV modules is presented in Table 7.

Table 5. PV modules list

\begin{tabular}{cccc}
\hline \multicolumn{2}{c}{ Photovoltaic Types } & Rated power (W) & Efficiency \\
\hline Manufacturer & Model & 300.303 & $18.4 \%$ \\
SunPower & SPRE18300com & 300.456 & $18.28 \%$ \\
Aleo Solar & P19Y300 & 300.115 & $18.44 \%$ \\
AU Optronics & PM060MBR & 300.115 & $18.44 \%$ \\
Auxin Solar & AXN6M610T300 & 300.348 & $18.42 \%$ \\
AXITEC & AC300M60S & 300.104 & $18.44 \%$ \\
Boviet SolarTech & BVN6610M300 & 300.384 & $18.31 \%$ \\
First Solar & TS300R1102 & 300.018 & $18.97 \%$ \\
Flextronics & FLVMA300P60AB & 300.024 & $18.29 \%$ \\
Yingli Energy & YL300D30B & & \\
\hline
\end{tabular}

By applying hourly solar radiation data into all PV moduls with taking into consideration the temperature effects and tilted angle (Kalogirou, 2009) and the result in Table 8 shows that the power generated by First Solar is more than the rest of the brands. Therefore, this type of PV is selected. The data for First Solar and its cost estimation, which is 2.49 \$/W is taken from the NREL report (Fingersh, Hand, \& Laxson, 2006). A total of 960 design simulations has been made using the LPSP method to arrive at the best combination values of PV panels, wind turbines and batteries with no power loss (LPSP $=0$ ) and with a low LCOE. The results showed that a higher wind turbine capacity gave a better option as they give higher power production at lower speeds.

Table 6. PV modules price comparison

\begin{tabular}{cccc}
\hline \multirow{2}{*}{ PV module } & & Photovoltaic Output & \\
\cline { 2 - 3 } & Watt/ year/ unit & Effecincy (dust) & Watt/ year/ unit \\
\hline Sunpower & 845678.80 & 0.95 & 803394.87 \\
Aleo Solar & 835081.36 & 0.95 & 793327.29 \\
AU Optronics & 842631.91 & 0.95 & 800500.31 \\
Auxin Solar & 842631.91 & 0.95 & 800500.31 \\
AXITEC & 836012.5 & 0.95 & 794211.87 \\
Boviet & 844462.41 & 0.95 & 802239.29 \\
First Solar & 861539.2 & 0.95 & 818462.24 \\
Flextronics & 848891.06 & 0.95 & 806446.51 \\
Yingli Energy & 853090.10 & 0.95 & 810435.59 \\
\hline
\end{tabular}


Table 7. Simulation tests at Sharourah city

\begin{tabular}{|c|c|c|c|}
\hline \multicolumn{2}{|c|}{ Battery Capacity } & \multirow{2}{*}{$\begin{array}{c}\text { Simulation } \\
\text { (tests or runs) }\end{array}$} & \multirow{2}{*}{$\begin{array}{c}\text { No. of tests passed } \\
(\operatorname{LPSP}=0)\end{array}$} \\
\hline hours & $\mathrm{kWh}$ & & \\
\hline 24 & 350 & 240 & 240 \\
\hline 12 & 175 & 240 & 240 \\
\hline 6 & 87.5 & 240 & 6 \\
\hline 0 & 0 & 240 & 0 \\
\hline
\end{tabular}

At Sharurah city (table 9), the results from the simulations show that the batteries with 6, 12 and 24 hours capacity can achieve zero power loss and 486 out of 960 tests has passed the simulation; the simulations show that the (KVA WIND 10-15) wind turbine passes the simulation test with zero LPSP and lower LCOE. The payback time for the chosen system was found to be within 11 years when compared with the diesel generator power system as can be seen in Figure 6.

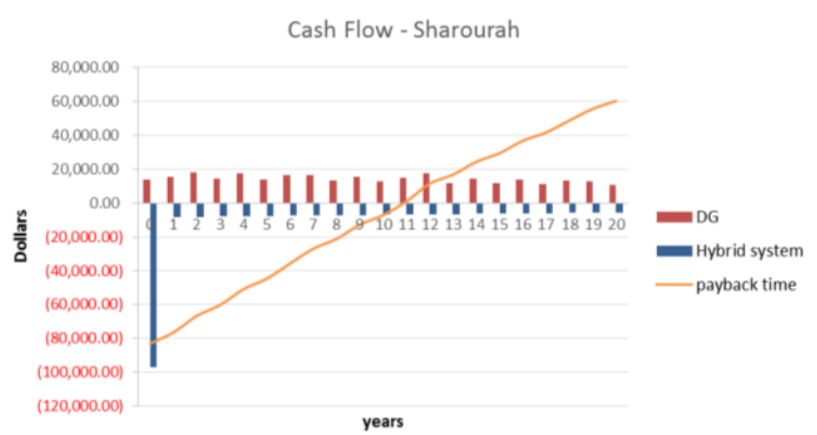

Figure 6. Cash flow of selected configuration at Sharourah
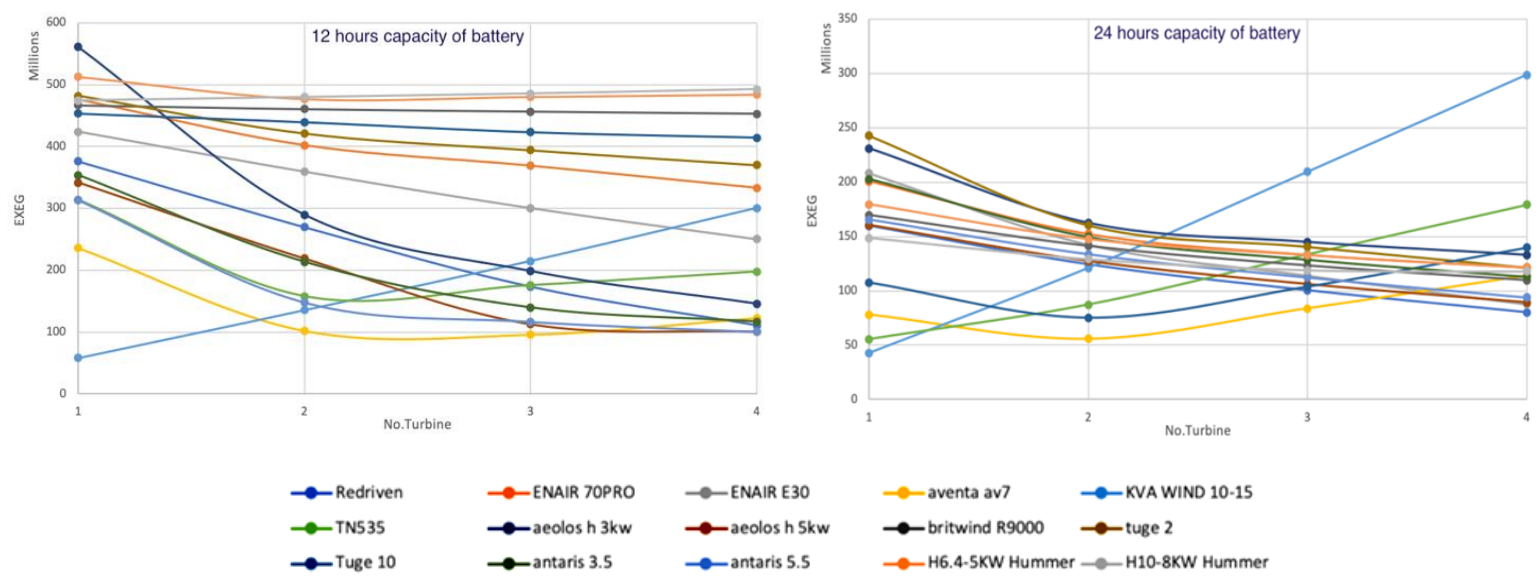

Figure 7. Wind turbine vs excess energy at Sharourah

Figure 7 shows the relationship between the number of wind turbines and energy excess at a hub height of 40 meters, it can be noticed that the excess energy can be reduced by increasing the number of the wind turbine, also the excess energy can be reduced by choosing the higher capacity of battery meaning the 24 hours is better than 12 hours. the same observation was captured at a hub height of 60, 80 and 100 meters and as the hub hight increased the excess energy decreased.

Figure 8 shows the relation between a wind turbine and PV panels quantities along and the differences of 24 and 12 hours of battery capacities, it can be noticed that the higher the capacity of a wind turbine the lower the quantity of PV panels, also, increasing the quantity of wind turbine tend to reduce the PV panels quantity, furthermore, the higher the battery capacity the lower the quantity of wind turbine and PV panels. the same observation was captured at a hub height of 60, 80, and 100 meters. As well as increasing the height of the hub of wind turbine tend to decrease the PV panels quantity. 


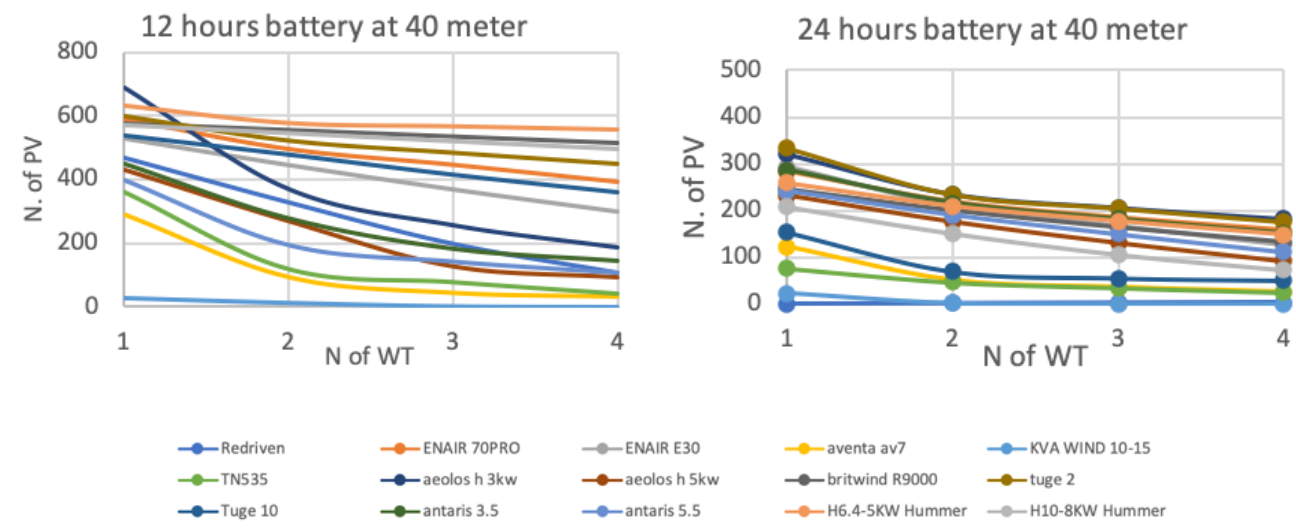

Figure 8. Wind turbine vs PV panels at Sharourah

A similar procedure was adopted for Hafer Al-Batin. The results from the simulations show that the batteries with 12 and 24 hours capacity can achieve zero power loss and 252 out of 960 tests has passed the simulation as can be seen on Table 10; The simulations show that two (KVA WIND 10-15) turbines with 22 PV panels and 12 hours of battery storage is the best system with an excess energy of $74 \%$ out of the total energy production which can be reduced to $66 \%$ by shutting down the turbine when the PV produced power produces the required power. The payback time for this site is 20 years when compared with the diesel generator power system as can be seen in Figure 9.

Table 10. Simulation tests at Hafar Albatin city

\begin{tabular}{|c|c|c|c|}
\hline \multicolumn{2}{|c|}{ Battery Capacity } & \multirow{2}{*}{$\begin{array}{c}\text { Simulation } \\
\text { (tests or runs) }\end{array}$} & \multirow{2}{*}{$\begin{array}{c}\text { No. of tests passed } \\
(\mathrm{LPSP}=0)\end{array}$} \\
\hline hours & $\mathrm{kWh}$ & & \\
\hline 24 & 350 & 240 & 240 \\
\hline 12 & 175 & 240 & 12 \\
\hline 6 & 87.5 & 240 & 0 \\
\hline 0 & 0 & 240 & 0 \\
\hline
\end{tabular}

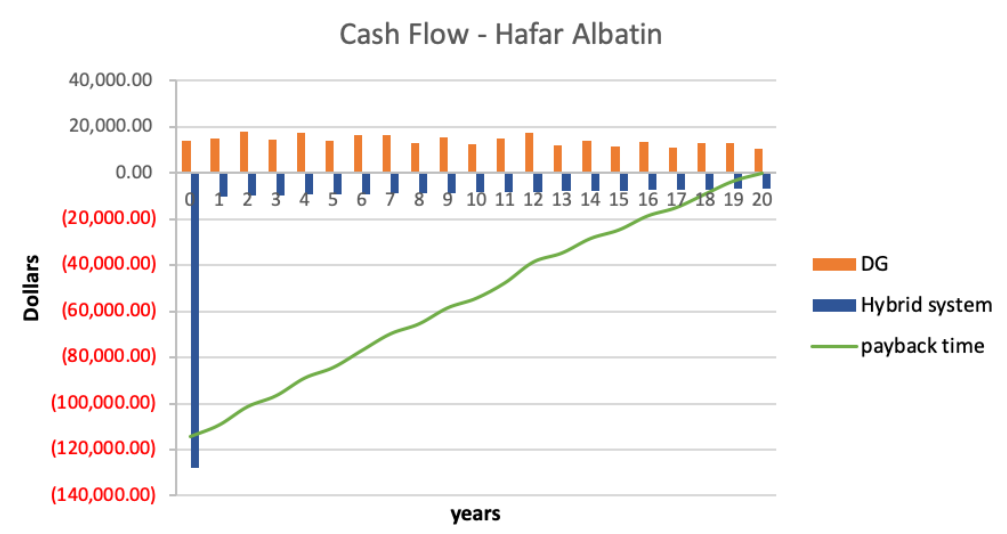

Figure 9. Cash ow of selected configuration at Hafar Al-Batin

Simulations for the configurations of the two sites were also run using HOMER software; with applying the same input data, all system components, assumptions, and constraints; the results matched the ones obtained in this study with negligible minor differences. Finally, the best selected hybrid systems for both locations in terms of lower Levelized cost of energy "LCOE" are presented in Table 11. 
Table 11. Selected economic hybrid systems at the two sites

\begin{tabular}{ccc}
\hline Item & $\begin{array}{c}\text { Sharourah } \\
\text { Quantity and Description }\end{array}$ & $\begin{array}{c}\text { Hafar Al-Batin } \\
\text { Quantity and Description }\end{array}$ \\
\hline \multirow{3}{*}{ Wind turbine } & One turbine, & Two turbine, \\
& KVA WIND 10-15 & KVA WIND 10-15 \\
at $40 \mathrm{~m}$ hub height & $\mathrm{at}$ hub height \\
PV panel & 27 First Solar Panels & 22 First Solar Panels \\
& 58 units, $175 \mathrm{kWh}$, & 58 units, $175 \mathrm{kWh}$, \\
Batteries & PVX-2120L with 12 & PVX-2120L with 12 \\
& hour storage capacity & hour storage capacity \\
LCOE & $0.33 \$ / \mathrm{kWh}$ & $0.414 \$ / \mathrm{kWh}$ \\
NPC & $\$ 236571$ & $\$ 296633$ \\
Payback period & 11 years & 20 Years \\
\hline
\end{tabular}

\section{Conclusions}

A hybrid wind and solar PV system with a load capcity of $5 \mathrm{~kW} / \mathrm{h}$ has been designed in two selected regions in Saudi Arabia. Technical and cost aspects have been included and evaluated. The main findings of this work can be summarized as follows:

1) Hafar Al-Batin shows higher wind speeds than Sharourah by $53 \%$ whereas Sharourah shows higher solar radiation than Hafar Al-Batin by almost $60 \%$.

2) The simulation result shows that in both Sharourah and Hafar Al-Batin, continuous power supply without any power loss can be generated.

3) Sharourah is more suitable for the implementation of the hybrid system than Hafar Al-Batin in terms of lower LCOE and lower energy excess.

4) KVA WIND 10-15 wind turbine is the best suited wind turbine for both locations.

5) Solar First PV panels are the best panels for both locations.

6) PVX-2120L battery is better suited for the hybrid combination.

7) The payback times were 11 and 20 years for Sharourah and Hafar Al-Batin, respectively.

8) The analytical method and HOMER shows similar results.

9) The energy excess can be reduced by increasing the storage capacity of the batteries.

10) Increasing the number of wind turbines tends to reduce the energy excess for wind turbine capacity less than $10 \mathrm{~kW}$ and viseversa.

11) The number of PV panels is the main factor of energy excess.

12) The tower height of the wind turbine tends to reduce the energy excess.

\section{Acknowledgments}

The authors would like to acknowledge the support, assistance, guidance provided by King Abdullah City for Atomic and Renewable Energy (KACARE) alonge with King Saud University (KSU) and Sustinable Energy Technologies Center (SET) at King Saud University.

\section{References}

Al Garni, H. Z., \& Awasthi, A. (2017a). A Fuzzy AHP and GIS-based Approach to Prioritize Utility-Scale Solar PV Sites in Saudi Arabia. IEEE International Conference on Systems. https://doi.org/10.1109/SMC.2017.8122783

Al Garni, H. Z., \& Awasthi, A. (2017b). Solar PV power plant site selection using a GIS-AHP based approach with application in Saudi Arabia. Applied Energy, 206, 1225-1240. https://doi.org/10.1016/j.apenergy.2017.10.024

Al Sharafi, A. (2011). Modeling and analysis of hybrid pv/wind off grid power generation system in the kingdom of Saudi Arabia (Master's thesis, King Fahd University, Dhahran, Saudi Arabia). https://eprints.kfupm.edu.sa/id/eprint/138438/

Al-Abbadi, N. M., \& Rehman, S. (2009). Wind Speed and Wind Power Characteristics for the Gassim Saudi 
Arabia. International Journal of Green Energy, 6, 201-217. https://doi.org/10.1080/15435070902785068

Al-Ghussain, L., Ahmed, H., \& Haneef, F. (2018). Optimization of hybrid PV-wind system: Case study Al-Tafilah cement factory, Jordan. Sustainable Energy Technologies and Assessments, 30, 24-36. https://doi.org/10.1016/j.seta.2018.08.008

Allhibi, H., Chowdhury, H., Zaid, M., Loganathan, B., \& Alam, F. (2019). Prospect of wind energy utilization in Saudi Arabia: A review. Energy Procedia 160, 746-751. https://doi.org/10.1016/j.egypro.2019.02.184

Almarshoud, A. F. (2016). Performance of solar resources in Saudi Arabia. Renewable and Sustainable Energy Reviews, 66, 694-701. https://doi.org/10.1016/j.rser.2016.08.040

Almasoud, A. H., \& Gandayh, H. M. (2015). Future of solar energy in Saudi Arabia. Journal of King Saud University, Engineering Sciences, 27, 153-157. https://doi.org/10.1016/j.jksues.2014.03.007

Alqahtani, F. (2016). Analysis of the Potential of Renewable Energy Development in Saudi Arabia (Master's thesis, West Virginia University, Morgantown, West Virginia, USA). https://doi.org/10.33915/etd.5084

Bekele, G., \& Tadesse, G. (2012). Feasibility study of small Hydro/PV/Wind hybrid system for off-grid rural electrification in Ethiopia. Applied Energy, 97, 5-15.

Benghanem, M. (2011). Optimization of tilt angle for solar panel: Case study for Madinah, Saudi Arabia. Applied Energy, 88, 1427-1433. https://doi.org/10.1016/j.apenergy.2010.10.001

Bhattacharjee, S., \& Acharya, S. (2015). PV-wind hybrid power option for a low wind topography. Energy Conversion and Management, 89, 942-954. https://doi.org/10.1016/j.enconman.2014.10.065.

Breza, P. (2013). Modelling and simulation of a PV generator for applications on distributed generation systems (Doctoral dissertation, TU Delft, Delft University of Technology). Retrieved from http://resolver.tudelft.nl/uuid:259fa81e-fa57-48f3-802a-f209f1e74006

Diaf, S., Diaf, D., Belhamel, M., Haddadi, M., \& Louche, A. (2007). A methodology for optimal sizing of autonomous hybrid PV/wind system. Energy Policy, 35, 5708-5718. https://doi.org/10.1016/j.enpol.2007.06.020

Dzimano, G. (2008). Modeling of photovoltaic systems (Master's thesis, The Ohio State University). Retrieved from http://rave.ohiolink.edu/etdc/view?acc_num=osu1228307443

Elhadidy, M. A., \& Shaahid, S. M. (2007). Wind resource assessment of eastern coastal region of Saudi Arabia. Desalination, 209, 199-208. https://doi.org/10.1016/j.desal.2007.04.029

Eltamaly, A. M. (2013). Design and implementation of wind energy system in Saudi Arabia. Renewable Energy, 60, 42-52. https://doi.org/10.1016/j.renene.2013.04.006

Esmail, M. A., Abdullah, A., Habib, M. A., \& Iyad, A. (2015). A New Study for Hybrid PV/Wind off-Grid Power Generation Systems with the Comparison of Results from Homer. International Journal of Green Energy, 12, 526-542. https://doi.org/10.1080/15435075.2013.833929

Fingersh, L., Hand, M., \& Laxson, A. (2006). Wind Turbine Design Cost and Scaling Model. National Renewable Energy Laboratory. https://doi.org/10.2172/897434

Fingersh, L., Hand, M., \& Laxson, A. (2006). Wind Turbine Design Cost and Scaling Model. National Renewable Energy Laboratory. https://doi.org/10.2172/897434

Fu, R., Remo, T., \& Margolis, R. (2018). 2018 U.S. Utility-Scale Photovoltaics-Plus-Energy Storage System Costs Benchmark. National Renewable Energy Laboratory. https://doi.org/10.2172/1483474

Kalogirou, S. (2009). Solar Energy Engineering: Processes and Systems. Elsevier. https://doi.org/10.1016/B978-0-12-374501-9.X0001-5

Lee-Jones, D. (2016). Feasibility Study of Building Integrated Hybrid Solar Pv and Wind Power Systems: A Case-Study On the Swedish Island of Gotland (Master's thesis, Uppsala University, Uppsala, Sweden). Retrieved from http://uu.diva-portal.org/smash/record.jsf?pid=diva2\%3A1194627

Manwell, J. F., McGowan, J. G., \& Rogers, A. L. (2009). Wind Energy Explained (2nd ed.). Wiley. https://doi.org/10.1002/9781119994367

Manwell, J. F., McGowan, J. G., \& Rogers, A. L. (2009). Wind Energy Explained (2nd ed.). Wiley. https://doi.org/ 10.1002/9781119994367

Martin, C. L., \& Goswami, D. Y. (2005). Solar Energy Pocket Reference. International Solar Energy Society. 
https://doi.org/10.4324/9781315781389

Md. Mahbub, A., Rehman, S., Meyer, J., \& Al-Hadhrami, L. M. (2011). Wind speed and power characteristics at different heights for a wind data collection tower in Saudi Arabia. World Renewable Energy Congress, Wind Energy Application, 4082-4089. https://doi.org/10.3384/ecp110574082

Mills, D. (2004). Advances in solar thermal electricity technology. Solar Energy, 76(1-3), 19-31. https://doi.org/10.1016/S0038-092X(03)00102-6

Mokheimer, E. M. A., Sahin, A. Z., Al-Sharafi, A., \& Ali, A. I. (2013). Modeling and optimization of hybrid wind-solar-powered reverse osmosis water desalination system in Saudi Arabia. Energy Conversion and Management, 75, 86-97. https://doi.org/10.1016/j.enconman.2013.06.002.

Rafique, M. M., Rehman, S., Md. Alam, M., \& Alhems, L. M. (2018). Feasibility of a 100 MW Installed Capacity Wind Farm for Different Climatic Conditions. Energies, 11, 2147. https://doi.org/10.3390/en11082147

Rehman, S. (2005). Prospects of wind farm development in Saudi Arabia. Renewable Energy, 30, $447-463$. https://doi.org/10.1016/j.renene.2004.04.008

Rehman, S., \& Ahmad, A. (2004). Assessment of wind energy potential for coastal locations of the Kingdom of Saudi Arabia. Energy, 29, 1105-1115. https://doi.org/10.1016/j.energy.2004.02.026

Rehman, S., \& Sahin, A. Z. (2014). Comparing the Use of Diesel and wind Power for Pumping Water in Saudi Arabia. Energy \& Environment, 25(2), 369-388. https://doi.org/10.1260/F0958-305X.25.2.369

Sahin, A. Z., Rehman, S., \& Al-Sulaiman, F. (2017). Global solar radiation and energy yield estimation from photovoltaic power plants for small loads. International Journal of Green Energy, 14(5), 490-498. https://doi.org/10.1080/15435075.2016.1278374

Samrat, N. H., Ahmad, N., Choudhury, I. A., \& Taha, Z. (2015). Technical Study of a Standalone Photovoltaic Wind Energy Based Hybrid Power Supply Systems for Island Electrification in Malaysia. PLOS ONE, 10(6). https://doi.org/10.1371/journal.pone.0130678

Shahid, S. M., Al-Hadhrami, L. M., \& Rahman, M. K. (2013). Economic feasibility of development of wind power plants in coastal locations of Saudi Arabia. Renewable and Sustainable Energy Reviews, 19, $589-597$. https://doi.org/10.1016/j.rser.2012.11.058

Tlili, I. (2015). Renewable energy in Saudi Arabia: current status and future potentials. Environ Dev Sustain 17, 859-886. https://doi.org/10.1007/s10668-014-9579-9

Yang, A. H., Shen, H., \& Liao, X. (2003). Computer-aided design of PV/wind hybrid system. Renewable Energy, 1491-1512. https://doi.org/10.1016/S0960-1481(03)00011-9

Zella, E., Gasim, S., .. \& Al Subie, M. (2015). Assessment of solar radiation resources in Saudi Arabia. Solar Energy, 119, 422-438. https://doi.org/10.1016/j.solener.2015.06.031

\section{Copyrights}

Copyright for this article is retained by the author(s), with first publication rights granted to the journal.

This is an open-access article distributed under the terms and conditions of the Creative Commons Attribution license (http://creativecommons.org/licenses/by/4.0/). 